\title{
The Imperative of Logic in Composition and Writing
}

\author{
Samuel Asuquo Ekanem, Ph.D \\ Centre for General Studıes, Cross River Uiıversity of Technology Calabar - Nigeiıa \\ Eton Dien Simon, Ph.D \\ Centre for General Stuiies, Cross River University of Technology Calabar - Nigeria
}

\section{Doi:10.5901/ajis.2014.v3n4p473}

\begin{abstract}
Logic as an academic discipline focuses on the science of reasoning, inference and proof. However, these are different goals from it practical application in composition and writing. Most writers appear to ignore the importance or value of logic as a veritable tool towards effective writing and composition. Whenever logic is employed in composition or writing the emphasis seems to be towards the determination of the reasoning behind an argument as either being valid or invalid and using same to support or reject a thesis. Though the goals are different, a degree of familiarity with logic and the structure of well-formed arguments and reasoning are very necessary and vital in assisting writers to construct valid arguments/reasoning to support their theses and the evaluation and refutation of invalid arguments/reasoning employed in supporting others' theses. Indeed, the lack of the understanding of logic and its principles has been a problem to effective writing and composition. Without a sound logic, there cannot be intellectually stimulating writing and composition. This has been the bane of scholarly writing and composition. It is on the basis of this therefore that we will examine the simple basics of logical argument, types of argument, some of the mistakes that are likely to be made when logic is used incorrectly. We will at the end establish the functionality and imperative of logic.
\end{abstract}

\section{Introduction}

A sound, well reasoned and compelling argument is one of the most effective and persuasive communicative acts that human beings ever create. As academics, scholars and writers, it is imperative that we learn enough about logic so as to be properly equipped to employ stronger and more consistent argument in our research, work and writing.

Without a sound knowledge of logic there cannot be coherency in any writing. Logic is therefore a fundamental and veritable instrument of effective writing, composition and even research. This is because, it is logic that shapes and creates the structure of any composition or writing. Also, it is logic that serves or functions as a bridge between the various ideas usually contained or expressed in a given writing, composition or research. Without effective and proper application of logic in a writing or composition the different ideas cannot be linked together to bring about a theme or central idea in a work. It is on the basis of this that logic becomes an imperative tool in composition and writing.

What we intend to do in this paper therefore, is to look at logic as a science of reasoning that aids writers in being creative in the generation of ideas. So, what will be done here is a discussion of some of the uses of logic that writers employ in creating persuasive or argumentative essays. Here, we will examine the simple basics of logical arguments, some of the types of argument, and then some of the mistakes we will discover whenever logic is applied or employed incorrectly.

We also need to define certain terms here before we proceed. Argument here does not mean to fight, yell, shout, squabble or even brow-beat. Argument here refers to the process of reasoning through the advancement of proof. Argument as used in this paper has its root in logic.

\section{The Basics of Argument}

Logical arguments usually start with propositions. A proposition in logic is regarded or taken to be a statement that can either be true or false. Here are illustrations which will assist to explain this better.

i. "Calabar is the capital of Cross River state".

ii. "The people of Calabar speak Efik language". 
iii. "Jonathan is the first Nigerian to become the President of the country without contesting an election".

From the above, it is discoverable that when we use propositions, we are either asserting the truth of the statement or denying the truth of the statement. It must be stated here that, this is a technical meaning of "denying" and not its everyday usage or meaning. To deny in this context implies or simply means to gather evidence to show that the proposition cannot be true, and not just the fact that it is wrong. What is more, it is the meaning of the proposition that we assert or deny, and not the particular arrangement of words or the use of a specific word. Looking at our second example; for several people language is clearly synonymous with any communication system. So, under such an interpretation, people may deny the second proposition. For some others, language is one specific communicative system, with traits and features not found in any animal communicative system. In this case, some people may assert the second proposition as true. It is clear from here that precise "definition" and support evidence are vital and necessary in an argument, since the writer will be required to justify the assertions.

From this analysis, it is evident that propositions serve as the foundational element to the three parts of an argument, which are the premises, the inferences, and the conclusions.

\subsection{Propositions as Premises}

For a write, an argument starts with a proposition. So, one or more propositions become very fundamental and necessary for the argument to continue. These propositions must be stated or expressed explicitly, and these are referred to as the premises or the argument. These premises are what could be termed the grounds or reasons for accepting the argument and its conclusions. A writer must as a matter of necessity has evidence that can support the assertion. Where a writer for any reason of error fails to explicitly state his/her premises, the audience is most likely to be suspicious about the strength of the writer's supporting evidence and this has the capacity to affect the credence of the writer's argument negatively (Ucheaga, 2004).

Premises or assertions are usually indicated by certain phrases like because, obviously and so on. However, words like certainly, surely, obviously are really problematic in an argument. This is because as a group, they are generally known as the language of certitude. The language of certitude can be employed to fool others into accepting dubious premises just by attempting to convince the readers that the premise is true beyond question through the use of intimidation, the fear of querying the "certainty" of a premise for fear of appearing foolish, ill-informed, or even ignorant. So, it is this fear of embarrassment that lures or intimidates some people into not querying or raising questions about a premise that is asserted to be "obvious", and that use of intimidation is how the language of certitude operates (Pitt, 2006).

\subsection{Propositions as Inferences}

Ekanem (2008) posits that a writer uses the premises of the argument to derive further propositions, which are known as inferences. Inferences are the propositions that are entailed. (It must follow logically) if the premises are true. There are certain logical principles or rules that are usually followed to derive valid inferences, which are known as implicature or "truth table". So, we think of inferences and implicature, it is important to remember the vital point that: the fact that a deductive argument is valid does not in any way make it mandatory for the conclusion to hold, or the fact that a deductive argument's conclusion is true does not in any way mean that its premises are true equally. This unusual situation derives from the often counter-intuitive nature of implicature (Wikipedia, 2010).

Usually, a valid argument according to Uduigwomen (2005) consists of true propositions, true premises combining with true inferences that lead to a true conclusion. That appears logical. However, it can equally happen that an argument can reach a true conclusion based on one or more false premises eg.

- Blacks exist in Africa (premise)

- Africans are white (false premise)

- Therefore whites exist in Africa (conclusion).

What is worse is that an argument may at times be completely valid if it contains only false propositions. For instance:

- All dogs have spots (false premise)

- Tigers are dogs (false premises)

- Therefore all tigers have spots (false conclusion).

From our example here, it is seen that the conclusion is not true because the argument's premises are false. But if 
the argument's premises were true, the conclusion would have been true. However, technically, the argument is entirely valid. Through all these seem strange, we can depend on one outcome that cannot reach a false conclusion derived through true inference from true premises.

Accordingly, based on these examples, and others, logicians created what is known as "truth table" for implicature that matches premise to conclusion through inference. In the table below, the symbol " $=>$ " denotes implication; $A$ is the premise, $\mathrm{B}$ the conclusion. $\mathrm{T}$ and $\mathrm{F}$ represent true and false respectively.

\begin{tabular}{|c|c|c|}
\multicolumn{3}{|c}{ Premise conclusion inference } \\
\hline $\mathrm{A}$ & $\mathrm{B}$ & $\mathrm{A}=>$ \\
\hline $\mathrm{F}$ & $\mathrm{F}$ & $\mathrm{T}$ \\
\hline $\mathrm{F}$ & $\mathrm{T}$ & $\mathrm{T}$ \\
\hline $\mathrm{T}$ & $\mathrm{F}$ & $\mathrm{F}$ \\
\hline $\mathrm{T}$ & $\mathrm{T}$ & $\mathrm{T}$ \\
\hline
\end{tabular}

It should be noted that if the premises are false and the inference valid, the conclusion can be either true or false.

Also, if the premises are true and the conclusion false, the inference must be invalid.

Again, if the premises are true and the inference valid, the conclusion must be true.

To conclude this section of the paper, it is important we make one last distinction: there is a technical difference between a valid argument and a sound argument. A valid argument according to Ucheaga (2004), is an argument whose conclusions follow from its premises, but it is an argument whose conclusions may not be true, (as shown above) because its premises may not be true. A sound argument on the other hand, is a valid argument whose premises are true. To Ekanem (2008) a sound argument therefore arrives at a true conclusion. It is on the basis of this that logicians and rhetoricians are careful not to confuse sound arguments with valid arguments.

So, when we read the works of others, we have to think more than just the soundness of an argument. Arguments are usually presented as part of a larger context that is, a context in which the author has some particular purpose or objective in mind. These "hidden arguments" are part of the persuasive nature of writing as well as these explicit arguments that we compose. Just as we evaluate the argument itself, we should equally evaluate the ethical and emotional appeals with the intent of the argument.

\subsection{Fallacies as Errors}

Since we have completed this brief overview of the traditional structure of argument, it is pertinent we look at some of the ways that argument is misused in writing or even in debate. What we intend to do here is highlight some of the common pitfalls and fallacies we should avoid when writing or constructing an argument. But before we proceed, it is important that we make some clarification. Fallacy as a concept or a term in common usage implies or refers to mistaken belief as well as error and faulty reasoning. But in logic, the term is basically used to mean only a form of technically incorrect argument, especially if that argument appears to be valid or convincing. In this paper therefore, we define fallacy as a logical argument or rhetorical device that seems to be sound but is actually and truly unsound when viewed or examined closely. So, our study of fallacies will prevent use not to be misled by them. The fallacies we are looking here at are those usually used in argumentative essays.

\subsubsection{Accent}

Where a writer attempts to change the meaning by changing the emphasis that is, the focus or accent, then the writer is committing an error or fallacy of reasoning. So, accent is an attempt to persuade by shifting meaning and focus away from one issue to another issue.

For example, let's compare these:

- We should support those candidates that support our programmes.

\subsubsection{Ad hoc}

This type of fallacies arises when writers try to give "after-the-fact explanations" for conclusions, rather than present premises and inferences that lead to those conclusions.

- Although we said we had proof that the Militants had weapons in the creeks, and although we found no 
evidence that they really did, Militancy in the Niger Delta was justified because their leader was a terror.

\subsubsection{Affirmation of the Consequent}

Whenever a writer composes an argument that has the form of $A$ implies $B ; B$ is true; therefore $A$ is true, the writer is strictly speaking committing a fallacy of affirming the consequent. It is very possible to reach a correct, true conclusion despite false premises. This can be seen in the truth table we earlier discussed. So, it is fallacious to argue that if $B$ is true, A must necessarily be true also.

\subsubsection{Amphiboly}

This type of fallacy occurs when a writer uses ambiguous, vague or unclear premises. Once this happens in any writing then the writer is guilty of amphiboly.

\subsubsection{Appeal to humour}

This happens when a writer attempts to sway the readers through the application of humour, instead of premises, inferences and evidence. Humour has that interesting ability to allow us see the issue(s) or the world from the humourist perspective. For instance, if a boy and a girl (who are lovers) happen to be watching the Lagos comedy club show on television, and one of the comedians makes a sexist joke, and the boy laughs, one can appreciate why the girl may be upset. The implication of the boy laughing is that the boy shared the sexist world view of the comedian for that moment. This could be the case even if the boy has never shown any sign of sexist behaviour before. Here, if a writer is able to humorously construct proposition, he or she may be able to attract readers to that perspective without any need of supplying evidence or premises.

\subsubsection{Argumentum ad antiquitatem/Appeal to Tradition}

When a writer argues for the merits of a proposition, it is the traditional position to follow, then such a writer is guilty of appeal to tradition. It is a fact that often times we do things for good reasons; sometimes we do things just because we always do them. This indeed is the nature of appeal to tradition. Example;

- I am totally against the idea of a proposal that radically alter the tradition of the Church... A woman cannot wear trousers and leave her head uncovered to enter the Church.

A Church like the Catholic Church should be unaffected by fashionable whims in the name of Pentecostalism.

\subsubsection{Argumentum ad baculum/Appeal to Force}

This is the case where a writer employs coercion, intimidation, threat or hint of potential fear to manipulate the readers into accepting his/her conclusion. This is often used in politics and can be captured with such phrase like "might makes right". This can be directly or indirectly.

- The 2007 election in Nigeria is a do or die affair and the PDP as the ruling party will crush all opposition parties.

- The kidnappers said we have to make the money available or they will harm the Vice Chancellor.

- Let Jonathan contest the 2011 election and face the wrath of the North.

\subsubsection{Argumentum ad hominem}

Argumentum ad hominem simply means an "argument directed at was the man" not his ideas, evidence, arguments, or beliefs. This usually happens when the writer attacks the person or group making the assertion, instead of attacking the person's evidence, assumptions, premises, inferences, or conclusions. This is not only a faulty logic, since the validity or soundness of an argument does not depend on the personal characteristics of the person who makes it, it is equally a bad rhetorical strategy since it is very easy to beat.

- Humanism is an evil philosophy. It is practiced by sinners, sadists and slanderers.

From here it is seen that there is no direct connection between the arguments of humanism and the people who 
propose those arguments. This is fallacious. This is because it is not proper to reject an argument simply because we reject those that make the argument. This is very similar to "social identification".

We are familiar with the tactics of lawyers who will sometimes cast doubt upon the testimony of a witness in a court of law by declaring that such a witness is a known perjurer. This is not clearly an ad hominem attack, but rather, it is a valid way to reduce the credibility of the testimony given by the witness. This does not show that the witness's testimony is false. So, to think that it does is to fall into the web of "argumentum ad ignorantiam".

So, when a writer uses certain fact of the opponent's particular situation, than that writer will be guilty of applying the circumstantial form of "argumentum ad hominem". For instance someone may say or argue thus:

- It is indeed an established fact for a person to steal food if the person is poor. So how can you think otherwise when you are very rich.

- You'll certainly support sex before marriage, just because you're a man.

\subsubsection{Argumentum ad ignorantiam}

This simply means" argument from ignorance". Whenever a writer argues that something has to be or may be real just because there is no evidence to the contrary, then that writer is simply employing "argumentum ad ignorantiam". This type of fallacy asserts the truthfulness of a proposition just on the basis that this is no evidence in the contrary:

- God is real because no one can prove otherwise.

This type of fallacy can not be used by lawyers in a court of law, where an accused is assumed innocent until proven guilty. Under this circumstance therefore, a defendant cannot be asked to prove he/she is not guilty. Again, in science, when it is known that some event would produce a particular evidence of its occurrence, so the absence of such evidence can validly be used to infer that the event did not happen. This can be compared to shifting the burden of proof.

\subsubsection{Argumentum ad Misericordiam/Appeal to Pity}

This happens when a writer presents the evidence in such a way that it has the strongest emotional impact possible on the audience regardless of the soundness or validility of the evidence, such a writer is therefore appealing to the emotions in this fallacy, that is, appeal to pity. The technique usually adopted is that the writer employs the readers' sense of pity to encourage the reader to accept his/her conclusion. This can be illustrated thus:

- The right thing to do is for our political leaders to donate to charity. The poor people in the society will all die without your donation.

\subsubsection{Argumentum ad Popullum}

This is a technique or a situation where a writer attempts to persuade the readers by asserting that the majority of people feel in a certain way about an issue or a particular thing. Where this is the case, then the writer is guilty of argumentum ad popullum, which is equally known as appealing to the people. Also, where the writer tries to win acceptance of an assertion through appealing to beliefs of a large group of people, then such a writer is employing argumentum ad popullum. Again, this fallacy is usually couched with emotive language such as:

- Fifty Millions Nigerians use GLO, Fifty Millions Nigerians cannot be wrong. Join the GLO team.

\subsubsection{Non Sequitur}

This fallacy is committed where a writer draws conclusions from premises that are not logically connected to the conclusion. Where this happens, such a writer commits a fallacy known as non sequitur (Uduigwomen, 2005).

\section{Conclusion}

From our analysis, discourse and examples, it is clear that writers commit a lot of errors or fallacies through the way they construct or present their arguments. To avoid this error or pitfall in writing, it is important that writers learn, understand and appreciate the science of logic. Through the proper understanding of logic, writers can be better equipped to construct their arguments in flawless propositions that will not generate criticisms.

It is on the basis of this that this paper strongly advocates for the introduction of logic into the various levels of the 
educational system starting from the primary school. This will lay a solid foundation for effective writing. It will also assist writers to settle the contentious issue of distinction between argumentative and persuasive writing. This is because argumentative writing uses "rational appeal" alone, while persuasive writing uses all three of Aristotelian appeals.

\section{References}

Copi, I. M. (2002) Introduction to Logic. Upper Saddle River, N.J: Prentice Hall . Downes, Stephen "Fallacies" http!//onegoodmove.org/Fallacy/Index.htm.

Ekanem, S. A. (2008) A Systematic Approach to Philosophy and Logic, Calabar: Samaroi Publishers.

Read, D. H. C. (1983) Letter to the New York Times, January 13, P. 14.

Rottenberg, A. T. (1994) The Structure of Argument. New York: Palgrave Macmillan.

Schick, T. and Lewis V. (1998) How to Think About Weird Things: Critical Thinking for a New Age, $2^{\text {nd }}$ ed, New York: Mayfield. Ucheaga, D. N. (2004) Rudiment of Logic Port Harcourt: Diamond Publications.

Uduigwomen, A.F. and Ozemba, G.O. Eds. A Concise Introduction to Philosophy and Logic, Calabar: Centaur Publishers. The Internet Encyclopedia of Philosophy. "Deductive and Inductive Arguments" http!//onegoodmove.org/fallacy/index.htm. The Internet Encydopedia of Philosophy "Fallacies"http://www.iep.utm.edu/fallacy/July 10th, 2010. 